\title{
Prácticas de reducción de núcleos en Punta de la Peña (Antofagasta de la Sierra, Catamarca): un análisis de los distintos modos de trabajar las rocas en contextos de aprovisionamiento
}

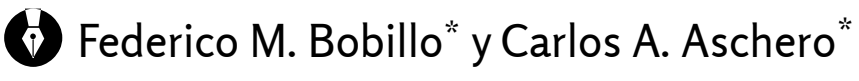

\section{Resumen}

Los sitios cantera presentan un registro lítico diverso que se vincula con distintos procedimientos técnicos empleados por las personas para extraer materias primas necesarias para la subsistencia. El presente estudio tuvo por objeto analizar la diversidad de procedimientos y prácticas empleadas por los/as talladores/as para efectuar la reducción de núcleos en canteras. Para ello, se efectuaron prospecciones sistemáticas, muestreos y un análisis técnico-tipológico de conjuntos de núcleos de dos canteras de vulcanitas (PPZAC y POZAC), situadas en la localidad de Punta de la Peña (Antofagasta de la Sierra, Catamarca). Como parte de este estudio se registraron distintos grupos de núcleos (de lascados aislados, poliédricos, bifaciales, nucleiformes, entre otros) que presentan técnicas de talla particulares, entre ellas: talla simple, bifacial, multifacial y centrípeta; además de núcleos que poseen tratamientos específicos de las plataformas de percusión y de los frentes de extracción. A partir de esta investigación se registraron prácticas individuales o colectivas y los "modos de hacer específicos" que se llevaron a cabo en los sistemas tecnológicos vinculados al aprovisionamiento lítico en canteras de vulcanitas.

Core reduction practices at Punta de la Peña (Antofagasta de la Sierra, Catamarca): an analysis of the different ways of working stones at procurement contexts
Recibido:

13 de marzo de 2018

Aceptado:

12 de julio de 2018

\section{Palabras clave}

Aprovisionamiento lítico Canteras

Prácticas de reducción Núcleos

Análisis técnico-tipológico Estrategias tecnológicas

\begin{abstract}
Quarry sites present a variable lithic record that is linked to the different technical procedures used by people in extracting the necessary raw materials for subsistence. The purpose of this study was to analyze the diversity of procedures and practices used by knappers for core reduction at quarries. To this end, systematic surveys, sampling, and a techno-typological analysis of cores from two quarries (PPZAC and POZAC) were carried out. We identified different core types (isolated flakes cores, polyhedral cores, bifacial cores, flake-cores, among others) that present particular knapping techniques:
\end{abstract}

\section{Keywords}

Lithic procurement Quarries

Reduction practices Cores

Techno-typological analysis Technological strategies 
simple, bifacial, multifacial and centripetal. In addition, cores with specific treatment of the percussion platforms and the core face were documented. From this study, individual or collective practices and "specific ways of doing" that formed part of the technological systems linked to lithic procurement at volcanic rocks quarries were recorded.

\section{Introducción}

Las materialidades que componen los contextos líticos de canteras se generan a partir de prácticas tecnológicas que implican la percepción, juicios y destrezas del practicante (Ingold, 2000). En este sentido, el accionar de los/as artesanos/as en situaciones de aprovisionamiento conlleva un acto creativo y habilidoso (Ingold, 1990) y comprende una diversidad de conocimientos específicos y procedimientos técnicos que guían su accionar (Lemmonier, 1992; Sinclair, 2000). Así, las canteras y canteras-taller se constituyen en sitios tradicionales e históricos, con múltiples eventos de uso y re-uso, que reúnen distintos tipos de prácticas tanto individuales como colectivas, gestadas durante milenios de explotación de materias primas (Barkai y Gopher, 2009; Barros, Messineo y Colantonio, 2015; Colombo, 2013; Messineo y Barros, 2015; Shipton, Petraglia y Paddayya, 2009; entre otros). Siguiendo a Colombo (2013), en el presente estudio se considera que las canteras son sitios que presentan evidencias de extracción y recolección de rocas que cumplen el rol de materias primas y que poseen características favorables para la aplicación de una técnica de manufactura. Por otra parte, las canterastaller son "sitios en los que además de extraer o recolectar las rocas, se realizaron también actividades de reducción lítica o formatización de artefactos, es decir, cuando los talleres se emplazan en el mismo lugar que las canteras" (Colombo, 2013, p. 121).

En la Puna Argentina se llevaron a cabo diferentes investigaciones que tuvieron por objeto abordar temáticas vinculadas con: la identificación y análisis de fuentes de aprovisionamiento de materias primas, la proveniencia de los diversos tipos de rocas, el análisis de los atributos tecnológicos y tipológicos de los instrumentos confeccionados en cada una de ellas y la circulación de las mismas en distintas regiones (López, 2013; Mercuri y Glascock, 2010; Ratto, Orgaz, De la Fuente y Plá, 2002; Restifo y Patané Aráoz, 2017; Yacobaccio, Escola, Pereyra, Lazzari y Glascock, 2004; entre otras). Asimismo, se registraron distintos modos de trabajar los recursos líticos para el caso puneño. En este sentido, estudios desarrollados por Hoguin (2014) permitieron reconocer distintos tipos de desbaste de núcleos en la Puna (Susques, Jujuy), dando cuenta de diferentes procedimientos para extraer formas-base.

Particularmente, en la microrregión de Antofagasta de la Sierra (Catamarca) se llevaron a cabo numerosas investigaciones que tuvieron por objeto estudiar la organización tecnológica y los sistemas de producción lítica en sitios cazadores-recolectores y agro-pastoriles, abordando temáticas relacionadas con el aprovisionamiento y uso de recursos líticos para la confección de artefactos formatizados entre los 10.000 y los 1000 años AP (Aschero, Elkin y Pintar, 1991; Aschero, Escola, Hocsman y Martínez, 2002-2004; Aschero, Manzi y Gómez, 1993-1994; Elías, 2010; Escola, 2000, 2003; Funes Coronel y Martinez, 2013; Hocsman, 2006; Manzi, 2006; Martínez, 2003; Moreno, 2011; Pintar, 1996, 2014; Toselli, 1998, 1999; entre otros). Investigaciones recientes realizadas en una cantera y una cantera-taller de vulcanitas de la localidad arqueológica de Punta de la Peña permitieron conocer las dimensiones, formas y contenidos de los talleres líticos. Estos últimos presentan evidencias de "las primeras etapas de reducción (por ejemplo, testeo y formatización inicial de núcleos) o el proceso completo (extracción de lascas de los núcleos y formatización de artefactos con retoque)" (Colombo, 2013, p. 121). Como parte de estos estudios se desarrolló, además, la caracterización 
técnico-tipológica de los conjuntos que integran dichas áreas de producción (Bobillo, 2015, 2017; Bobillo y Hocsman, 2015). Sin embargo, temáticas vinculadas con los atributos morfológicos de las materias primas seleccionadas para la explotación, el conjunto de acciones físicas y las características de los procedimientos de reducción de núcleos se encuentran pendientes de ser analizadas en profundidad. Ante esta situación, a través del presente estudio se busca generar un aporte al conocimiento sobre los distintos modos de trabajar las rocas que los individuos emplearon en canteras de la Puna Argentina, considerando particularmente el caso de las canteras de Punta de la Peña en la microrregión de Antofagasta de la Sierra (Catamarca).

En consonancia con esto último, la presente investigación tiene por objeto estudiar la variabilidad de procedimientos técnicos empleados por los/as talladores/as durante milenios de aprovisionamiento de recursos líticos, analizando los criterios de selección de la materia prima a explotar, los métodos y técnicas de talla empleados durante la reducción de núcleos y los implementos utilizados para la acción (Lemmonier, 1992; Sinclair, 2000). La relevancia en el abordaje de este tipo de problemáticas surge a partir de entender a los materiales líticos de canteras como la expresión de prácticas y modos de hacer diversos, susceptibles de ser abordados a partir de un análisis técnico-tipológico.

\section{Reducción de núcleos en Zonas de Aprovisionamiento y Cantera de la localidad de Punta de la Peña}

En la localidad arqueológica de Punta de la Peña se localiza una cantera-taller de vulcanitas definida como Punta de la Peña Zona de Aprovisionamiento y Cantera (en adelante PPZAC). Esta se sitúa en el curso medio del río Las Pitas, en la parte superior de un farallón de ignimbritas (Toselli, 1998) (Figura 1). En la misma se localizan nódulos transportables de vulcanitas de buena calidad para la talla y artefactos que aparecen con densidades variables en distintos sectores de una superficie aproximada de $1,2 \mathrm{~km}$ por 1 km (Aschero et al., 2002-2004; Manzi, 2006). El registro lítico en el interior de PPZAC se encuentra conformado principalmente por percutores, núcleos y nucleiformes, desechos de talla y artefactos formatizados (Aschero et al., 2002-2004; Manzi, 2006; Toselli, 1999). Según los/as autores/as mencionados, dicha cantera-taller desempeñó un rol significativo como zona de aprovisionamiento de las ocupaciones prehispánicas que se asentaron en la localidad arqueológica de Punta de la Peña, ya que en ella se llevaron a cabo actividades de extracción de formas-base a partir de núcleos de tamaños medianos. Así, las actividades de aprovisionamiento tuvieron lugar como parte de un orden secuencial de producción (sensu Ericson, 1984) que involucró a PPZAC y las bases residenciales cercanas y/o lejanas (Aschero et al., 2002-2004; Pintar, 2014; Toselli, 1998, 1999). Investigaciones realizadas por Bobillo (2015, 2017), Manzi (2006) y Toselli (1999) en los contextos líticos de la cantera-taller permitieron documentar la presencia de núcleos poliédricos, fragmentos de núcleo, nódulos testeados y nucleiformes asociados a desechos de talla y artefactos formatizados. Dichos materiales fueron explotados con el objetivo de extraer formas-base con dimensiones inferiores a los $15 \mathrm{~cm}$ de longitud y ancho, las cuales se habrían usado para la formatización de artefactos en la cantera-taller misma o en sitios residenciales y/o logísticos emplazados en la localidad.

Por su parte, Pampa Oeste Zona de Aprovisionamiento y Cantera (en adelante POZAC) se sitúa en el curso medio-superior del río Las Pitas y se caracteriza por presentar nódulos transportables y bloques no transportables (Aschero et al., 2002-2004) (Figura 1). Los nódulos y bloques de vulcanitas de gran tamaño se distribuyen en una superficie aproximada de $13 \mathrm{~km}^{2}$ y muestran desprendimientos de lascas grandes por percusión arrojada (Bobillo, en prensa y discusión de este artículo). Estas lascas se habrían extraído para ser utilizadas como formas-base de otros tipos de núcleos o 
1. Debe considerarse que si bien POZAC se definió como un sitio principalmente cantera, investigaciones recientes permitieron registrar evidencias de actividades de formatización de artefactos en los contextos de reducción de núcleos (Bobillo, en prensa), por lo cual no se descarta que en POZAC hubieran ADT que podrían haber funcionado como canteras-taller. para los primeros estadios de reducción bifacial (Aschero, 1986, 1988; Aschero et al., 2002-2004; Pintar, 1996). Así, POZAC se definió como una cantera de extracción de formas-base ${ }^{1}$, donde predominó una selección de materiales de tamaños adecuados para su transporte y regularización y/o adelgazamiento en otros sitios (Aschero, 1986, 1988; Aschero et al., 1991; Aschero et al., 1993-1994; Pintar, 1996). Según Aschero (1986), los núcleos principalmente representados en la superficie de la cantera son poliédricos, discoidales irregulares y de extracciones bifaciales alternadas. Asimismo, recientes estudios realizados en POZAC evidenciaron núcleos poliédricos, núcleos de lascados aislados, nódulos testeados y nucleiformes, asociados a percutores y artefactos formatizados. Las actividades de reducción de núcleos estuvieron orientadas a extraer formas-base con dimensiones superiores o iguales a $10 \mathrm{~cm}$, es decir, lascas grandes/ muy grandes y anchas/muy anchas de acuerdo a los criterios definidos por Aschero (1975, 1983) (Aschero, 1986, 1988; Bobillo, 2015, 2017).

En relación a lo expresado, es importante tener en cuenta que las actividades de aprovisionamiento llevadas a cabo en la localidad de Punta de la Peña poseen una extensa profundidad temporal que se inicia en la transición Pleistoceno-Holoceno (10.000 años AP). Si bien PPZAC y POZAC son sitios superficiales que no cuentan con estratigrafía ni dataciones absolutas que posibiliten estimar una cronología, se han identificado comportamientos tecnológicos específicos y artefactos temporalmente sensibles que hicieron posible aproximar una edad relativa a los eventos de extracción de recursos (Bobillo y Hocsman, 2015). Así, se pudo establecer dos complejos de canteras (sensu Heldal, 2009): Complejo de cazadores-recolectores plenos y en tránsito a la producción de alimentos, o Complejo I (situado entre los 8000 y 3000 años AP aproximadamente), y Complejo de sociedades agro-pastoriles plenas, o Complejo II (situado entre los 1600 y 1200 años AP aproximadamente) (cf. Bobillo y Hocsman, 2015). La definición de estos complejos permitió corroborar que PPZAC y POZAC son sitios que fueron explotados durante una extensa secuencia temporal.

En el marco de estas observaciones, la presente investigación tiene por objeto profundizar el conocimiento sobre las prácticas de reducción de núcleos empleadas por los/as artesanos/as para extraer formas-base a través del tiempo. Los registros de los contextos líticos que yacen en PPZAC y POZAC evidencian distintas prácticas como parte de los métodos de debitage simple (sensu Inizan, Reduron-Ballinger, Roche y Tixier, 1999), utilizados en los procesos de reducción de núcleos. A través de estos métodos las formas-base se extraen sin que se efectúe una preparación especial del núcleo: las lascas se caracterizan por tener contornos y espesores variables, y formas que no son estereotipadas (Inizan et al., 1999). Al respecto, es preciso considerar que en las canteras de Antofagasta de la Sierra no se registraron procedimientos de reducción predeterminados (o complejos) como, por ejemplo, los métodos Levallois y/o de extracción de hojas (Inizan et al., 1999). En efecto, en el presente estudio se aborda la variabilidad de métodos de debitage simple en canteras, analizando a los núcleos como las "huellas materiales" de la expresión individual y/o social de los/as artesanos/ as en situaciones de aprovisionamiento (Sinclair y McNabb, 2005); en otras palabras, se examinan los distintos procedimientos individuales y/o colectivos utilizados en la reducción de núcleos y su expresión en la cultura material.

\section{Conformación de la muestra y metodología de análisis}

En PPZAC y POZAC se llevaron a cabo prospecciones pedestres a través de recorridos de transectas radiales y paralelas que tuvieron por objeto localizar los contextos líticos y describir los atributos tipológicos de los conjuntos artefactuales que los conforman (Bobillo, 2015, 2017). Por un lado, PPZAC presenta sectores con elevada densidad de materiales líticos tallados que forman Áreas Extensas de Talla (AET). Particularmente, 


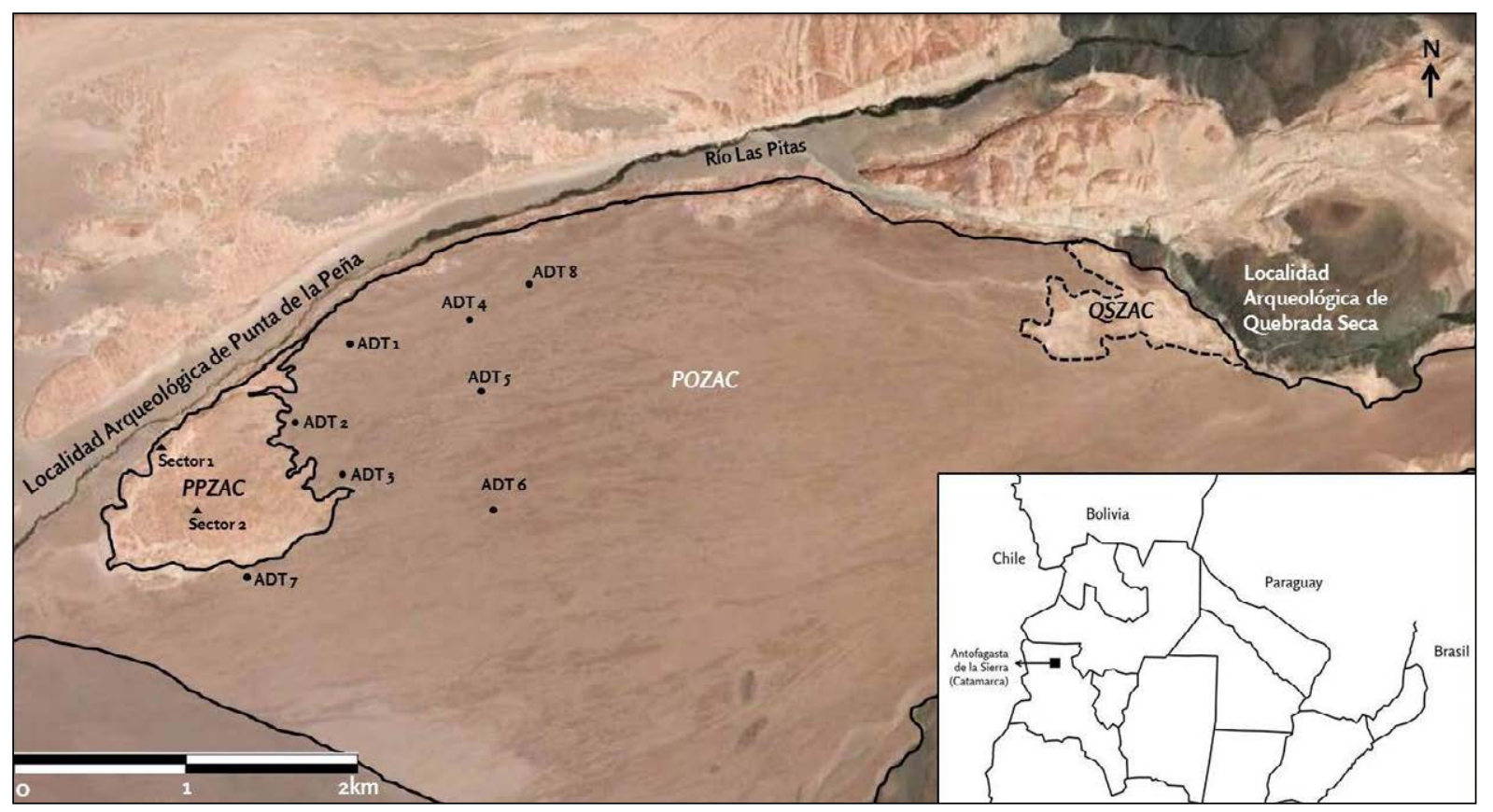

Figura 1. Localización de los contextos líticos muestreados en PPZAC y POZAC.

el Sector 1 se emplaza sobre terrazas rocosas de edad Plio-Pleistocena desarrolladas en ignimbritas (Tchilinguirian, 2008). Posee una elevada densidad de núcleos y nucleiformes, desechos de talla y artefactos formatizados distribuidos en una superficie aproximada de $55 \mathrm{~m}$ de largo por $25 \mathrm{~m}$ de ancho. Por otra parte, se localizó una segunda AET sobre la Planicie estructural de ignimbritas (Tchilinguirian, 2008). Esta también posee una elevada densidad de núcleos y nucleiformes, desechos de talla y artefactos formatizados. Se definió como Sector 2 y posee una dimensión aproximada de $100 \mathrm{~m}$ de longitud por $30 \mathrm{~m}$ de ancho. A los fines de la presente investigación, se efectuaron muestreos de núcleos en los Sectores 1 y 2 de PPZAC (Figuras 1 y $2 \mathrm{~A}$ y $2 \mathrm{~B}$ ) y se realizaron recolecciones superficiales de piezas aisladas en la planicie estructural de ignimbrita. Las muestras consideradas para el análisis técnico-tipológico y el lugar de proveniencia de las mismas se detallan en la Tabla 1.

Por su parte, en POZAC se seleccionaron ocho Áreas Discretas de Talla (ADT) para realizar muestreos de núcleos. Estas son el resultado de distintos eventos de explotación de bloques y nódulos de vulcanitas para extraer formas-base. Suelen poseer entre 4 y 10 metros de diámetro, con límites bien definidos en relación al suelo estéril circundante y menor cantidad de material lítico tallado en comparación con las AET registradas en PPZAC (Figuras 1 y 2C y 2D). En las ADT se empleó una doble estrategia para recabar información. Por un lado, se recolectaron núcleos transportables para su posterior análisis técnicotipológico en laboratorio. Por otro lado, se realizaron descripciones técnico-morfológicas in situ de aquellas piezas de gran porte que no son transportables como, por ejemplo, los núcleos de gran tamaño sobre bloques que poseen entre 40 y $90 \mathrm{~cm}$ de diámetro.

En función de los objetivos propuestos, en la presente investigación se efectuó un análisis técnico-tipológico (Aschero, 1975, 1983; Barros et al., 2015; Crabtree, 1972; Inizan et al., 1999; Martín Blanco, Jimenez Manzanares, Sanguino González y Gómez Laguna, 1994; Messineo y Barros, 2015; Morello, 2005; Santoja, 1984) sobre muestras de núcleos provenientes de ambas Zonas de Aprovisionamiento y Cantera (en adelante ZAC) $(\mathrm{n}=207)$ (Tabla 1). Específicamente, la muestra de PPZAC se encuentra compuesta por 142 núcleos, mientras que la cantidad de especímenes analizados de POZAC suma un total de 65 piezas; de todas estas, ocho corresponden a núcleos no diferenciados. 


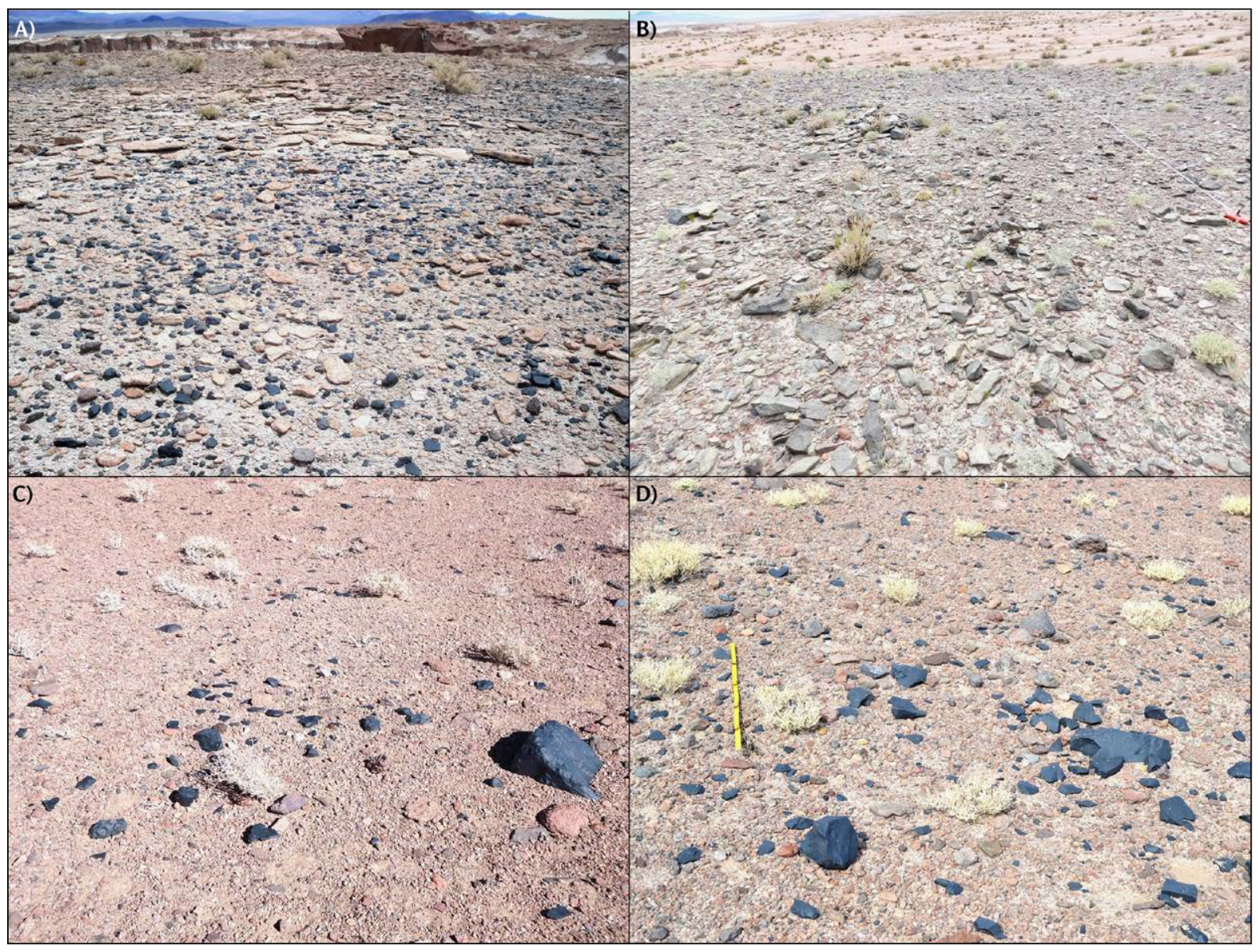

Figura 2. A) y B) Áreas Extensas de Talla (AET) en PPZAC; C y D) Áreas Discretas de Talla (ADT) en POZAC.

\begin{tabular}{|c|c|c|c|}
\hline Cantera & Proveniencia & Estrategia de registro & Núcleos (n) \\
\hline \multirow{3}{*}{ PPZAC } & Sector 1 & Muestreo y recolección & 64 \\
& Sector 2 & Muestreo y recolección & 67 \\
\hline \multirow{3}{*}{ POZAC } & Planicie estructural de ignimbritas & Recolección de piezas aisladas & 11 \\
& ADT 1 & Muestreo y recolección & 6 \\
& ADT 2 & Muestreo y recolección & 5 \\
& ADT 3 & Muestreo, recolección y registro in situ & 7 \\
& ADT 4 & Muestreo, recolección y registro in situ & 9 \\
& ADT 5 & Muestreo, recolección y registro in situ & 6 \\
\hline Total & ADT 6 & Muestreo, recolección y registro in situ & 14 \\
\hline
\end{tabular}

Tabla 1. Muestra sobre la que se efectuó el análisis técnico-tipológico y sectores de proveniencia en PPZAC y POZAC. 


\section{Resultados}

\section{Métodos y técnicas de talla aplicados a la reducción de núcleos en PPZAC y POZAC}

Como punto de partida, se observa que las materias primas principalmente explotadas en PPZAC y POZAC son las vulcanitas variedades 1 (91\%) y 5 (8\%). Durante el aprovisionamiento los individuos desarrollaron distintas formas de conceptualizar el recurso y manipularlo en función de la búsqueda de formas-base. Esta diversidad de prácticas utilizadas para reducir la materia prima se evidenció a partir del hallazgo de distintos tipos de núcleos (Tabla 2). A continuación se hace referencia a las características técnico-tipológicas de los distintos grupos registrados en talleres superficiales de las ZAC.

\section{Grupo de núcleos de lascados aislados y poliédricos}

Estos tipos de núcleos ( $\mathrm{n}=83$ ) (Figura 3) promedian dimensiones próximas a los 10 $\mathrm{cm}$ de longitud y anchura (Tabla 3 ), registrándose casos particulares que alcanzan los $33 \mathrm{~cm}$ de longitud, $39 \mathrm{~cm}$ de ancho y $16 \mathrm{~cm}$ de espesor. Las formas-base empleadas son nódulos rodados, facetados y tabulares (73\%), además de lascas externas e internas (16\%). Al respecto, es preciso considerar que en la superficie de POZAC se pudo constatar el uso de bloques de vulcanitas inamovibles con tamaños entre 40 y $90 \mathrm{~cm}$ para extraer formas-base. El producto de esta explotación son núcleos de lascados aislados y/o poliédricos sobre bloques de gran porte.

En cuanto a las características vinculadas con la explotación, se observa que los núcleos de lascados aislados tienden a presentar una baja cantidad de superficies aprovechadas como plataformas de percusión, generalmente no más de tres, y suelen ser corticales y lisas. El escaso número de plataformas aprovechadas sería el producto de una baja intensidad en la explotación de este tipo de piezas, considerando que sólo se extraen de dos a tres lascas para ser usadas como formasbase, en un $77 \%$ de los casos. Por otra parte, los núcleos poliédricos - y un núcleo globuloso- presentan de tres a siete superficies empleadas como plataformas de percusión, frecuentemente naturales, lisas y facetadas; suelen tener tres o más negativos de lascados sobre sus frente de extracción, contabilizándose más de 11 extracciones en algunos ejemplares.

El tamaño de las lascas que se obtienen a partir de estos núcleos es variable. Por un lado, se observa una tendencia a la extracción de formas-base pequeñas, medianas-pequeñas y medianas-grandes (entre uno y ocho centímetros) (51\%). Por otra parte, existe una marcada representación de negativos de lascado de tamaños grandes, muy grandes y grandísimos (entre ocho y más de 15 centímetros) (49\%) (Tabla 3). Estas últimas clases de lascas habrían sido extraídas a partir de núcleos sobre bloques facetados de grandes dimensiones, útiles para obtener formas-base de tamaños considerables al comienzo de la secuencia de reducción. Por su parte, los negativos de lascado tienden a ser unidireccionales - principalmente en núcleos de lascados aisladosmientras que los núcleos poliédricos tienden a presentar extracciones bidireccionales y multidireccionales. Estas últimas con mayor representación.

$\mathrm{Al}$ momento de ser descartadas las piezas sus plataformas de percusión presentan ángulos entre $60^{\circ}$ y $80^{\circ}$. El $71 \%$ de los núcleos no se encuentran agotados y un $89 \%$ de los mismos presentan la mitad —o más de la mitad - de sus superficies cubiertas con corteza. Entre las principales causas de abandono se encuentra la presencia de plataformas y frentes de extracción que dejan de ser aprovechables. 


\begin{tabular}{|l|c|c|}
\hline Tipos & N & $\%$ \\
\hline Núcleos de lascados aislados & 30 & 14,5 \\
Núcleos poliédricos & 52 & 25,1 \\
Núcleo globuloso (poliédrico agotado) & 1 & 0,5 \\
Núcleos bifaciales con lascados alternantes & 33 & 15,9 \\
Núcleos bifaciales con lascados no alternantes & 13 & 6,3 \\
Núcleos con extracciones unifaciales y bifaciales combinadas & 23 & 11,1 \\
Núcleos con extracciones unifaciales bidireccionales & 19 & 9,2 \\
Núcleos con extracciones unifaciales unidireccionales & 4 & 1,9 \\
Núcleos piramidales atípicos & 2 & 1,0 \\
Núcleo discoidal irregular o parcial & 1 & 0,5 \\
Nucleiformes & 21 & 10,1 \\
Fragmentos de núcleos no diferenciados & 8 & 3,9 \\
\hline Total & 207 & 100 \\
\hline
\end{tabular}

Tabla 2. Variabilidad de tipos de núcleos registrados en PPZAC y POZAC.

El tipo de reducción que presentan estos núcleos es unifacial (los golpes de percusión afectan un plano de extracción a la vez), de talla simple y multifacial (en las siguientes líneas se explican las particularidades de estos tipos de talla) (sensu Aschero, 1975, 1983; Martin Blanco et al., 1994). La primera de ellas (talla simple), característica de núcleos de lascados aislados, implica un bajo número de extracciones sin presentar planos de percusión preparados; en la muestra analizada sólo se registran dos casos que presentan preparación de las plataformas de percusión y de los frentes de extracción. Por otra parte, no se busca la explotación íntegra o exhaustiva del nódulo, ya que no suelen presentar negativos de lascados de extracciones previas frecuentes (Martin Blanco et al., 1994). La articulación de los lascados respecto a los bordes y las caras de las formasbase (sensu Aschero, 1975, 1983) suele ser mediante lascados unifaciales unilaterales (afectan una cara y parten de un borde) o bilaterales (afectan una cara y parten de dos bordes), incluso se observa un caso donde un núcleo presenta lascados multifaciales multidireccionales (determinan varias caras partiendo de múltiples planos). De todos estos atributos, el más frecuente en la mayoría de las piezas es el primero.

En relación con el segundo tipo de talla (multifacial), la misma es característica de los núcleos poliédricos y del único núcleo globuloso registrado. En estos núcleos los negativos de lascados se presentan con una frecuencia elevada; a medida que avanza la secuencia de reducción los negativos de extracciones previas se usan como plataformas de percusión para continuar la extracción de formas-base, produciéndose un permanente recorte y superposición de los negativos de lascado a medida que se utilizan y reutilizan los frentes de extracción (Martin Blanco et al., 1994). Por ello, en algunas piezas pertenecientes a este grupo de núcleos se observan plataformas de percusión facetadas. Entre el conjunto de núcleos poliédricos se encuentran núcleos poliédricos extendidos (presentan un contorno totalmente facetado con lascados multifaciales multidireccionales), poliédricos parciales (poseen un contorno parcialmente facetado) y globuloso (formas residuales) (Aschero, 1975, 1983).

\section{Grupo de núcleos de lascados bifaciales alternantes y no alternantes}

Los núcleos de este grupo $(\mathrm{n}=46)$ (Figura 4$)$ promedian dimensiones inferiores a los $10 \mathrm{~cm}$ (Tabla 3). Las formas-base son de distintos tipos: nódulos rodados, facetados y tabulares (36\%) y lascas externas e internas (46\%). Estas últimas (lascas externas 


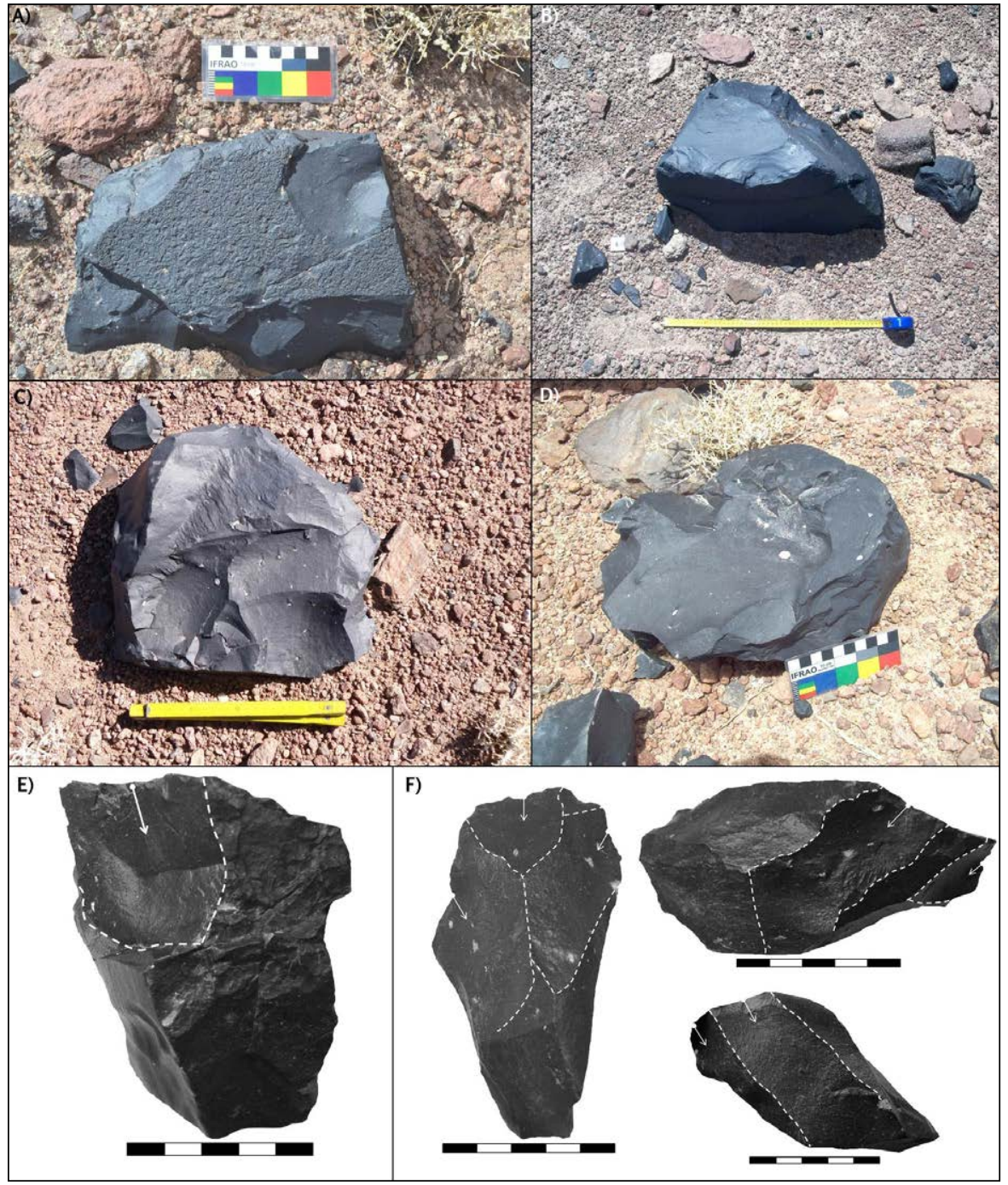

Figura 3. Núcleos de lascados aislados y poliédricos. A), B), C) y D) núcleos poliédricos y de lascados aislados sobre nódulos y bloques en sectores de pedimentos de POZAC; E) y F) núcleos poliédricos sobre nódulos.

e internas) poseen una mayor representación en el conjunto, lo que podría indicar una preferencia por este tipo de soportes para extraer formas-base; la disponibilidad de bordes o aristas con ángulos inferiores a los $90^{\circ} \mathrm{u} 80^{\circ}$ habría ofrecido plataformas aptas para realizar trabajos por percusión dura y/o blanda, ya sea de forma alterna o alternante. Asimismo, el $87 \%$ de las formas-base usadas como núcleos presentan secciones planoconvexas, biconvexas y romboidales irregulares en vista sagital, lo que indicaría una intención por parte de los/as talladores/as de explotar determinadas secciones en nódulos y lascas. En tal sentido, los individuos habrían buscado soportes que tuvieran morfologías particulares - por ejemplo, biconvexas y/o romboidales irregulares (ver esquemas en la Figura 4) - para extraer formas-base.

En relación al manejo de las piezas durante la explotación, se observa que las mismas tienden a presentar dos plataformas de percusión, con mayor frecuencia de tipo facetadas. No se observan plataformas corticales y hay una baja representación de plataformas lisas naturales y lisas. Esta ausencia sería el resultado de un proceso de reducción intensivo, donde las superficies con corteza o sin negativos de lascados previos se eliminarían a medida que avanza la secuencia de reducción. En consonancia 
con esta afirmación, en el 59\% de los casos se observan de tres a nueve extracciones sobre los frentes de lascado, correspondiendo el porcentaje restante a objetos que tienen entre 10 y 18 negativos de lascado.

Las extracciones de los núcleos bifaciales tienden a ser pequeñas y medianas-pequeñas (54\%), seguidas en representación por lascas medianas-grandes (31\%), grandes (10\%), muy grandes (1\%) y grandísimas (4\%) (Tabla 3 ). A diferencia de lo observado para el caso de núcleos de lascados aislados y poliédricos, en este grupo no se registra una tendencia a la extracción de lascas con tamaños muy grandes y grandísimos, aunque sí se observa una frecuencia considerable de negativos de lascado medianosgrande y grandes. En conjunto, estos negativos se caracterizan por ser bidireccionales y multidireccionales sobre ambos frentes de extracción.

Por su parte, en la fase de abandono, se registran plataformas de percusión con ángulos entre $60^{\circ}$ y $80^{\circ}$. El $63 \%$ de los núcleos se descarta sin estar agotados, registrándose un total de 35 piezas que presentan la mitad o más de la mitad de sus superficies cubiertas con corteza. Las principales causas de abandono son: presencia de plataformas de percusión o frentes de extracción no aprovechables y terminaciones quebradas y en charnelas, entre otras.

Por último, este grupo de núcleos se caracteriza por una gestión bifacial del objeto, realizada a partir de un mismo plano o desde distintas superficies; el borde desde el que se realizan las extracciones representa el plano de intersección que divide en dos frentes distintos las superficies de lascado de las piezas (Martin Blanco et al., 1994). En la aplicación de este método de talla se tiende a emplear como punto de percusión la zona proximal del negativo de extracción previa situado en una de las dos caras del objeto (Martín Blanco et al., 1994; Santoja, 1984). Por su parte, al considerar la articulación de los lascados respecto a los bordes y las caras de las formas-base (sensu Aschero, 1975, 1983) se observan lascados bifaciales alternantes, es decir, que afectan dos caras del objeto alternándose sobre el borde. Por otra parte, se registran piezas que presentan extracciones alternas (afectan dos caras, una partiendo de un borde y otra partiendo del borde alterno). Así, se hace evidente que dentro de los procedimientos de reducción bifacial de núcleos existieron distintos modos de manipular las plataformas de percusión y de efectuar las extracciones de lascas. Por último, al considerar las formas que presentan estas piezas con frecuencia se observan contornos convexilineos, ovaliformes o elípticos.

\section{Grupo de núcleos con extracciones unifaciales y bifaciales combinadas}

En lo que refiere a este conjunto $(\mathrm{n}=23)$ (Figura 5), las dimensiones de las piezas promedian tamaños inferiores a los nueve centímetros (Tabla 3). Del mismo modo que se documentó para el caso de los núcleos bifaciales, en estas piezas tienden a emplearse como formas-base lascas externas e internas con mayor frecuencia (57\%) y, en segundo lugar, nódulos rodados, facetados o tabulares (39\%). Asimismo, las lascas y nódulos empleados como formas-base presentan secciones específicas (Hocsman, comunicación personal, 2016), entre ellas planoconvexas (48\%) y romboidales irregulares o biconvexas asimétricas (52\%). Al igual que lo planteado con anterioridad para el caso de los núcleos bifaciales, en estos soportes se habrían aprovechado determinadas morfologías y secciones para extraer lascas desde los distintos frentes de extracción (Hocsman,t comunicación personal, 2016).

Con respecto a las plataformas de percusión, se registra el empleo de dos superficies de impacto en la mayoría de las piezas. Estas son de tipo natural, liso-natural, lisas, diedras y facetadas, siendo estas últimas las de mayor representación en el conjunto. Aproximadamente la mitad de la muestra posee entre tres y ocho negativos de lascado sobre los frentes de extracción (48\%), correspondiendo el porcentaje restante a especímenes que poseen de 10 a 15 extracciones. Como se ha planteado para los 
A)
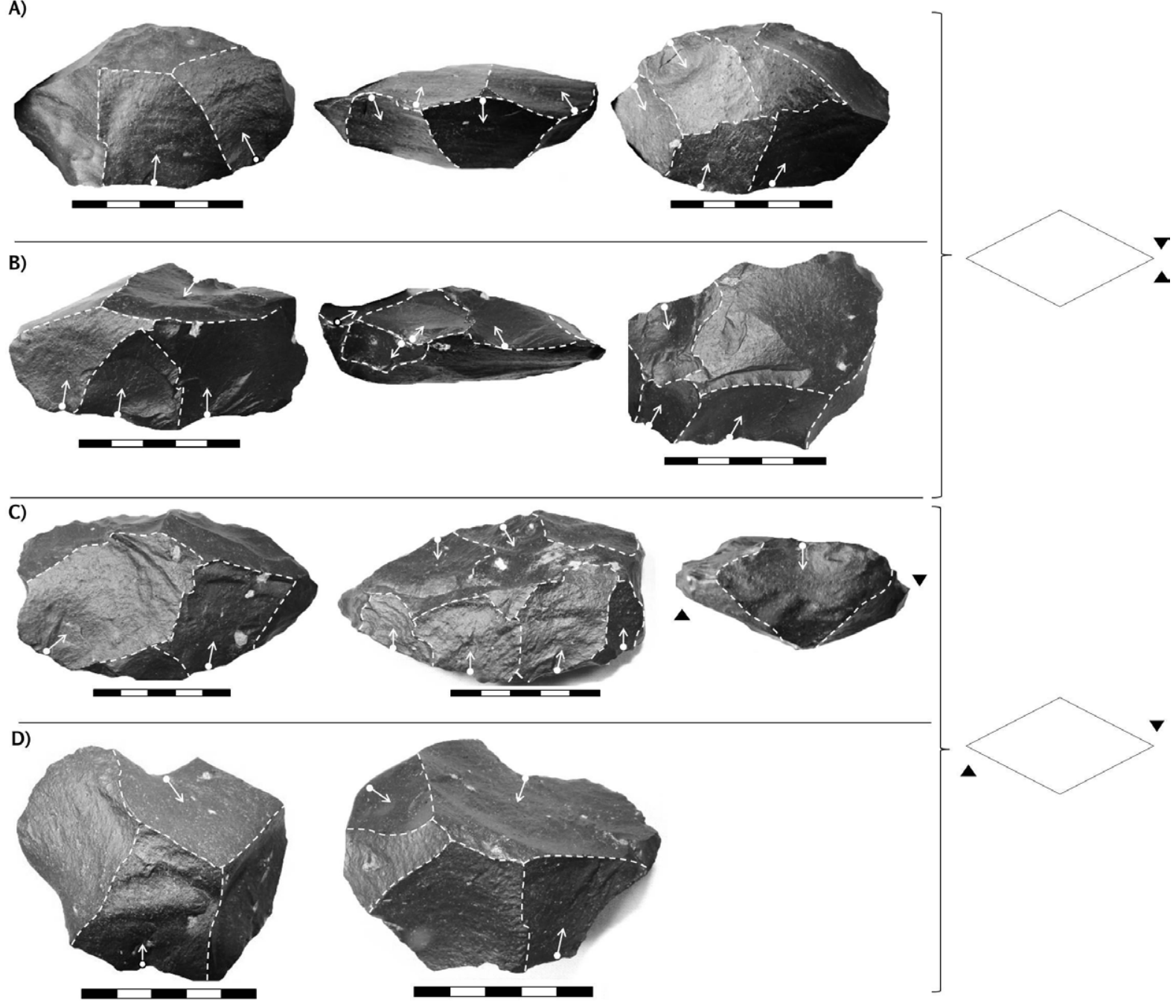

Figura 4. A) y B) núcleos de lascados bifaciales alternantes: los lascados afectan las dos caras del objeto alternándose sobre el borde; C) y D) núcleos de lascados bifaciales no alternantes (alternos): los lascados afectan las dos caras, una partiendo de un borde y otra partiendo del borde alterno.

casos de núcleos poliédricos y bifaciales, este conjunto habría estado sujeto a procesos de reducción intensivos durante los procedimientos de extracción de formas-base, considerando el elevado número de negativos de lascado sobre las superficies trabajadas.

En relación a este último aspecto, las lascas extraídas suelen ser medianas-pequeñas (40\%), medianas-grandes (29\%) y pequeñas (17\%) con mayor frecuencia. Existe una baja representación de negativos de lascado que den cuenta de una búsqueda de lascas grandes (14\%) para ser utilizadas como formas-base, aspecto que distingue a este conjunto de los grupos anteriores. En este caso particular, no se documentan acciones orientadas a la extracción de lascas muy grandes ni grandísimas. Por su parte, en los frentes de extracción se observan negativos de lascados bidireccionales (con mayor frecuencia) y multidireccionales.

En lo que refiere al abandono de estas piezas, se observan plataformas de percusión que poseen ángulos entre $60^{\circ} \mathrm{y} 80^{\circ}$ en mayor medida. Asimismo, se registra una proporción prácticamente similar de núcleos que se descartan agotados (46\%) y no agotados (42\%) (el porcentaje restante corresponde a piezas no diferenciadas), lo que es coherente con lo postulado en párrafos anteriores sobre la intensidad de la reducción que poseen estos 
tipos de núcleos. En concordancia con esta última afirmación, el $82 \%$ se descarta con la mitad o menos de la mitad de sus superficies cubierta por corteza. Entre las causas de abandono se encuentra la presencia de plataformas o frentes no aprovechables, terminaciones en fractura o charnelas, astillamientos o machacados, engrosamientos de superficies que no se logran rebajar, entre otros.

Finalmente, este grupo de núcleos se caracteriza por un tipo de gestión particular, donde el tratamiento dado al objeto se distingue y diferencia de los demás grupos. La base de esta distinción radica en el manejo que los/as talladores/as realizaron de las plataformas de percusión y frentes de extracción, ya que se observan plataformas y superficies de lascado que fueron trabajadas unifacialmente desde un borde, mientras que el borde opuesto se talló de manera bifacial para realizar extracciones sobre ambos frentes de lascado. Así, el atributo tipológico distintivo de este grupo de piezas refiere a la combinación de extracciones unifaciales y bifaciales en un mismo objeto. En efecto, la articulación de los lascados respecto a los bordes y caras de las formas-base (Aschero, $1975,1983)$ se caracterizan principalmente por lascados unifaciales unilaterales, es decir, extracciones que afectan una cara y parten de un borde y lascados bifaciales unilaterales que afectan dos caras partiendo de un borde opuesto. Ambos tratamientos de las plataformas de percusión se documentan en la misma pieza.

Grupo de núcleos de extracciones unifaciales bidireccionales y unidireccionales sobre uno o más frentes de extracción

Este grupo de núcleos $(\mathrm{n}=23)$ (Figura 6) se encuentra integrado por aquellos materiales que en promedio poseen dimensiones inferiores a los siete centímetros (Tabla 3). Las formas-base son nódulos rodados, facetados y tabulares (26\%) y lascas externas e internas (57\%), también se registran también formas-base no diferenciadas de menor representación. Del mismo modo que se observó para los grupos anteriores existe una tendencia a seleccionar como soportes lascas sobre nódulos.

La mayor cantidad de los núcleos presentan de dos a tres plataformas de percusión (74\%), principalmente lisas, facetadas y diedras (53\%), seguidas en representación por superficies naturales y lisas naturales. En este conjunto se observan cuatro núcleos que poseen plataformas de percusión preparadas mediante extracciones de lascas. El fin de este procedimiento habría sido configurar planos para ser usados como puntos de impacto. Además, cuatro núcleos presentan regularización del borde de extracción mediante retoques complementarios de preparación y regularización del frente de extracción. $\mathrm{Si}$ bien estos atributos no son exclusivos de este grupo, su presencia refleja una intención por parte de los individuos de "acondicionar" los objetos durante los procesos de talla.

Por su parte, el total de negativos de lascado registrados en los frentes de extracción varía de uno a seis en el $57 \%$ de los casos, y el porcentaje restante pertenece a piezas que poseen entre siete y 14 negativos de lascados. En conjunto, se trata de lascados unidireccionales y bidireccionales principalmente, con tamaños pequeños $(42 \%)$ y medianos-pequeños (39\%) (Tabla 3). En relación con los grupos anteriores, se destaca que más del $40 \%$ de las extracciones se realizan en función de obtener lascas pequeñas. En consonancia con esto último, se registra una baja representación de negativos de lascado medianos-grandes (13\%), grandes $(3 \%)$ y muy grandes $(3 \%)$.

En cuanto a las características relacionadas con el abandono, se observa que las plataformas de percusión tienden a presentar ángulos entre $60^{\circ}$ y $80^{\circ}$ y un $78 \%$ de los casos presentan superficies con corteza. Además, los núcleos se descartan con plataformas de percusión y frentes de extracción no aprovechables y fracturas, entre otras causas. 

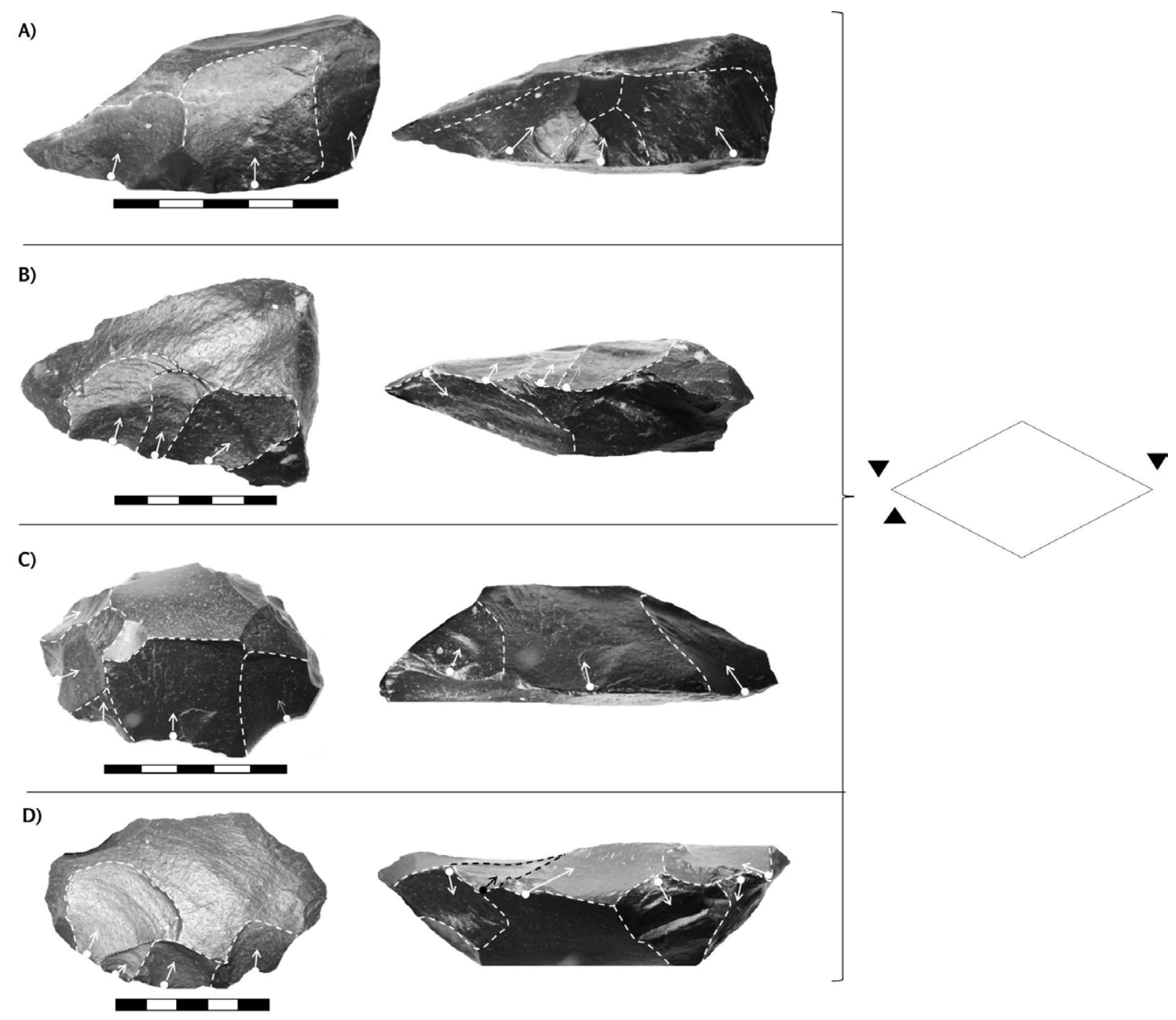

Figura 5. Núcleos con extracciones unifaciales y bifaciales combinadas. A) y C) extracciones unifaciales sobre una de las plataformas de percusión de las piezas $n^{\circ} 20$ y $n^{\circ} 80 ; B$ ) y D) extracciones bifaciales alternantes sobre una segunda plataforma de percusión en las piezas $n^{\circ} 20$ y $n^{\circ}$ 80 .

Para finalizar, es notable el tipo de gestión que presenta este grupo de núcleos, ya que se observan formas de manejar las superficies de extracción y las plataformas de percusión que son particulares. En este sentido, la articulación de los negativos de lascado respecto a los bordes y las caras de las formas-base (Aschero, 1975, 1983) tiende a ser unifacial bilateral (afectan una cara y parten de dos bordes) y/o unifacial unilateral (afectan una cara y parten de un borde). En relación a la primera forma de articulación, se documentan núcleos $(\mathrm{n}=18)$ cuyos frentes de extracción presentan negativos de lascados paralelos o sub paralelos sobre un único plano (unifaciales). Las extracciones tienden a ser bidireccionales $y$, generalmente, parten desde dos plataformas de percusión (preparadas o no) situadas en extremos opuestos al frente de extracción, conectándose o superponiéndose en el centro de dicho frente. Al respecto, debe considerarse un caso que presenta extracciones bidireccionales en más de un frente de extracción. Por otro lado, la segunda forma de articulación se presenta en piezas que poseen negativos de lascados unidireccionales y unifaciales. Dichas extracciones se realizan a través de una o dos plataformas de percusión. En conjunto, estas piezas manifiestan un tratamiento particular de las superficies de lascado y un manejo específico de los planos de impacto, distinguiéndose una forma variable de conceptualizar y manejar los soportes. 

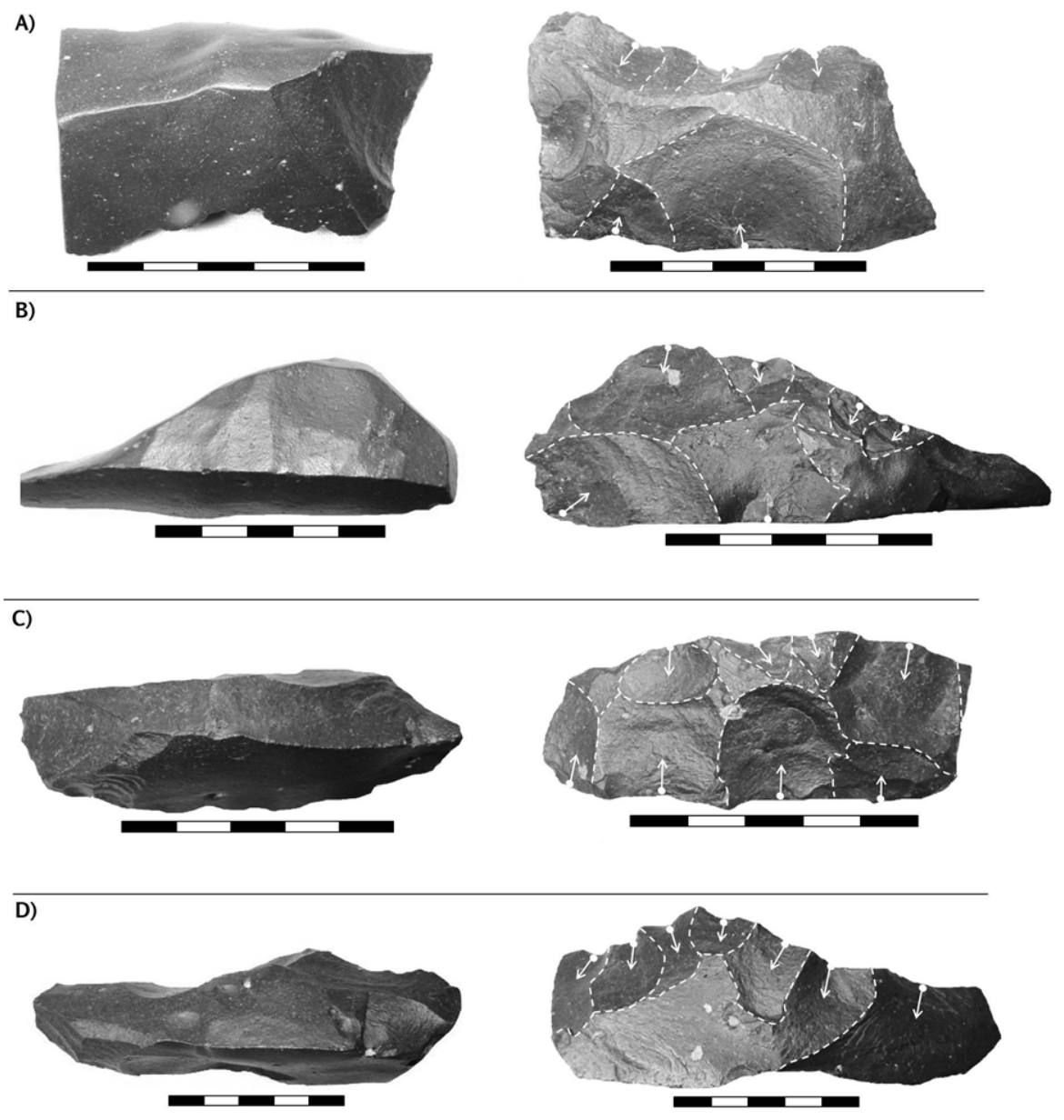

Figura 6. A), B) y C) núcleos de extracciones bidireccionales sobre un mismo frente de extracción; $D$ ) núcleo de extracciones unifaciales unidireccionales.

\section{Grupo de núcleos piramidales atípicos y núcleo discoidal irregular}

Como punto de partida debe considerarse que este grupo posee la menor cantidad de especímenes en relación al conjunto total y su distinción de los grupos restantes es evidente, ya que manifiestan procedimientos particulares para efectuar las extracciones y organizar las superficies de lascado (Figura 7 A, B y C). Concretamente, se trata de dos núcleos piramidales atípicos y un núcleo discoidal. El promedio de las dimensiones de estos es inferior a los ocho centímetros (Tabla 3), aunque debe considerarse que en el caso del núcleo discoidal se documentó una longitud de $15 \mathrm{~cm}$ y un ancho de 11 $\mathrm{cm}$, lo que difiere de los núcleos piramidales atípicos.

En cuanto a las formas-base empleadas se observa que, para el caso del núcleo discoidal, se utilizó un nódulo de vulcanita no diferenciado, mientas que los núcleos piramidales atípicos se redujeron a partir de núcleos poliédricos reciclados. En este sentido, en las piezas piramidales se observan extracciones orientadas a preparar plataformas de percusión desde las que se realizarán las extracciones unidireccionales, y asimismo, dichas extracciones recortan o se superponen a los negativos de lascados en antiguos frentes de extracción, correspondientes a los núcleos poliédricos reutilizados. Esto implica que antiguos núcleos poliédricos habrían sido retomados por los/as talladores/ as como núcleos piramidales atípicos; dicha afirmación se sustenta, principalmente, en la superposición de negativos de lascados (con una direccionalidad marcada) en distintos frentes de extracción. 
En lo que respecta a la cantidad de plataformas de percusión, se observa que los núcleos piramidales presentan una sola plataforma desde la que se efectúan las extracciones. Del mismo modo, el núcleo discoidal presenta una sola plataforma de percusión pseudoperimetral. En conjunto, el tipo de plano que se utiliza para efectuar las extracciones es facetado.

Al considerar la cantidad de negativos de lascado en los frentes de extracción se contabilizan de seis a ocho negativos en todos los casos. Las lascas que se extraen desde estos núcleos son medianas-pequeñas y pequeñas principalmente (56\%) (Tabla 3), seguidas en frecuencia por lascas grandes y muy grandes. Entre las causas de abandono de estas piezas se puede mencionar el agotamiento, con plataformas de percusión que presentan ángulos entre $60^{\circ}$ y $80^{\circ}$. Asimismo, la totalidad de estos núcleos poseen la mitad o menos de la mitad de sus superficies cubiertas con corteza.

En efecto, en este grupo se registran procedimientos de reducción que difieren entre sí, y a la vez, con los demás grupos. En lo relacionado con los núcleos piramidales atípicos, se observa que la articulación de los lascados respecto a las caras y los bordes de las formas-base (Aschero, 1975, 1983) es a través de lascados multifaciales unidireccionales que afectan varias caras partiendo de un único plano de percusión. Al respecto, debe tenerse en cuenta que estos núcleos no presentan los atributos típicos de los núcleos piramidales regulares que se utilizan para la extracción de hojas o láminas: piezas de forma ojival que presentan extracciones paralelas o sub-paralelas sobre los frentes de lascado, realizadas a partir de una plataforma de percusión perimetral poligonal, y en donde es característica la búsqueda de productos guiados por las aristas que determinan dos extracciones adyacentes (lascas laminares) (Aschero, 1975, 1983; Gallego y Rubio Jara, 1996; Inizan et al., 1999; Santoja, 1984; entre otros). Por el contrario, los núcleos piramidales atípicos poseen una morfología pseudo-piramidal que los distingue del resto de los grupos de núcleos y que se enmarca en un tipo de gestión particular. Particularmente, presentan una forma irregular y parcial, por lo que no pueden atribuirse al patrón piramidal de extracciones predeterminadas.

Por otra parte, el núcleo discoidal se caracteriza por lascados unifaciales perimetrales que afectan una cara y, prácticamente, la totalidad del borde. En este sentido, las extracciones de lascas se realizan desde el perímetro de la plataforma de percusión hacia el centro de la pieza, haciéndose uso de las facetas naturales del nódulo de vulcanita. El plano elegido como plataforma de percusión está conformado por restos de negativos de lascado realizados sobre la cara menos convexa del objeto. Si bien se observan características atribuibles a un manejo discoidal de la pieza no se incluye a este núcleo como discoidal típico o discoidal regular. En este sentido, no se documentan acciones de preparación de una superficie convexa ni un manejo de las extracciones para generar formas específicas en las superficies de desbaste del núcleo, tampoco se evidencia la extracción de productos con tamaños y morfologías predeterminadas (Boëda, 1993; Gallego y Rubio Jara, 1996; Inizan et al., 1999; Martín Blanco et al., 1994; Morello, 2005). Por todo esto, se decidió emplear la categoría de núcleo discoidal irregular para referir a un proceso de reducción particular y distinguible de los demás.

\section{Grupo de nucleiformes}

A este último grupo de núcleos $(n=21)$ pertenecen aquellas lascas que fueron seleccionadas por los individuos para extraer otros tipos de lascas (Figura 7D). Estas últimas habrían sido empleadas como formas-base de artefactos formatizados. Las dimensiones de los nucleiformes son variables, en promedio se registran piezas que poseen entre siete y nueve centímetros (Tabla 3), observándose longitudes extremas que alcanzan los $14,4 \mathrm{~cm}$ y anchos de hasta $15,7 \mathrm{~cm}$. Esto último evidencia que hubo 
una selección de lascas de gran tamaño (nodulares) para ser usadas como núcleos, las cuales se habrían extraído a partir de los bloques de grandes dimensiones (e inamovibles) presentes en POZAC. Por su parte, las formas-base usadas en este grupo de núcleos son lascas externas e internas, entre las que se pueden mencionar: primarias (24\%), secundarias (9\%), angulares con y sin reserva de corteza (43\%) y lascas no diferenciadas con reserva de corteza (19\%). El porcentaje restante corresponde a un artefacto formatizado usado como nucleiforme.

Cabe considerar que un $95 \%$ de los nucleiformes se caracterizan por presentar una sola plataforma de percusión empleada para extraer lascas. El tipo de plataforma más representado en la muestra son lisas (39\%), seguidas por facetadas (22\%), lisas naturales (17\%), naturales (11\%) y diedras (5\%). La mayor representación de plataformas lisas se vincularía con un aprovechamiento de la cara ventral o dorsal de las lascas seleccionadas como núcleos. Solo en dos casos se registraron acciones orientadas a regularizar el borde de extracción de los nucleiformes. Además, estas piezas presentan secciones planoconvexas en mayor medida (44\%), por lo que podría suponerse una intención de aprovechar estas morfologías para extraer lascas.

Dentro de este marco, así como se registra una baja cantidad de plataformas de percusión en la mayoría de los especímenes, también se documenta un bajo número de negativos de lascado sobre los frentes de extracción, dado que en un $90 \%$ de los casos se observa una sola extracción. Estas son de tamaños pequeños y medianos (Tabla 3 ) en mayor medida (63\%), lo que indica una tendencia a la búsqueda de lascas con dimensiones no mayores a los ocho centímetros.

Del mismo modo que se registró en grupos anteriores, los nucleiformes se descartan sin estar agotados (67\%). Asimismo, el 58\% de las piezas no presentan corteza o poseen la mitad o menos de la mitad de superficies cubiertas. El porcentaje restante corresponde a objetos que tienen más de la mitad de planos con corteza. En relación a las causas de abandono, se registran nucleiformes descartados con fracturas, plataformas y frentes de extracción no aprovechables, astilladuras y machacados en diferentes planos, entre otras. Al respecto cabe destacar que en un $33 \%$ de los casos no se pudo precisar la causa de abandono. Estos últimos casos poseen ángulos de plataformas de percusión mayores y menores a $60^{\circ}$, con una o dos plataformas potencialmente aprovechables sin evidencia de explotación. En conjunto, es factible suponer que estos nucleiformes podrían haber sido aprovechados con mayor intensidad, dada la ausencia de indicadores físicos que se puedan atribuir a "problemas" con en el material.

\section{Discusión y conclusiones}

A partir de esta investigación se logró recabar información sobre la diversidad de prácticas usadas por los individuos y grupos durante milenios de explotación de materias primas. En tal sentido, en la microrregión de Antofagasta de la Sierra existieron distintos modos de trabajar las rocas en canteras, prueba de ello es la diversidad de métodos de reducción de núcleos documentados en las piezas analizadas en PPZAC y POZAC.

Para comenzar, se observa una tendencia al aprovechamiento de grandes bloques de vulcanitas inamovibles (Figura 3). Estas piezas de gran tamaño se localizan sobre los sectores de pedimentos de POZAC y habrían implicado determinadas estrategias tecnológicas, acciones técnicas y posturas físicas de los/as talladores/as para extraer lascas útiles desde los frentes de extracción. Por un lado, para la reducción de los bloques de gran tamaño, inamovibles para una sola persona, se podrían haber desarrollado estrategias de explotación individuales, donde se aprovecharían las 
A)
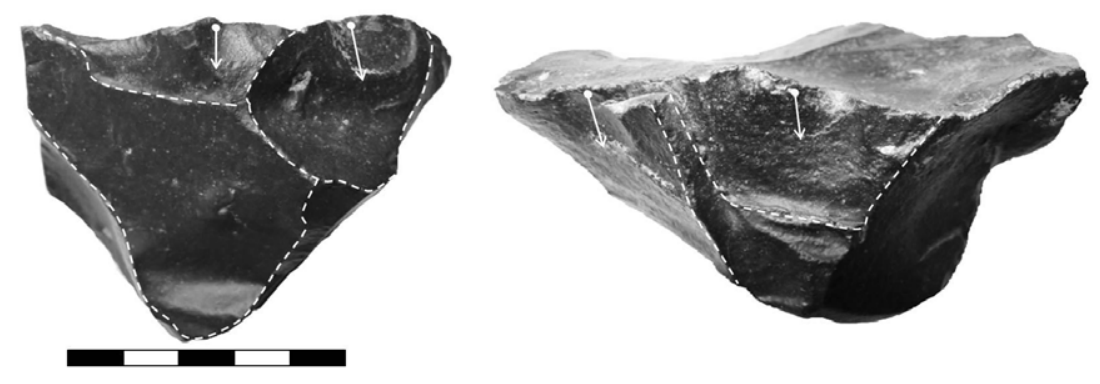

B)
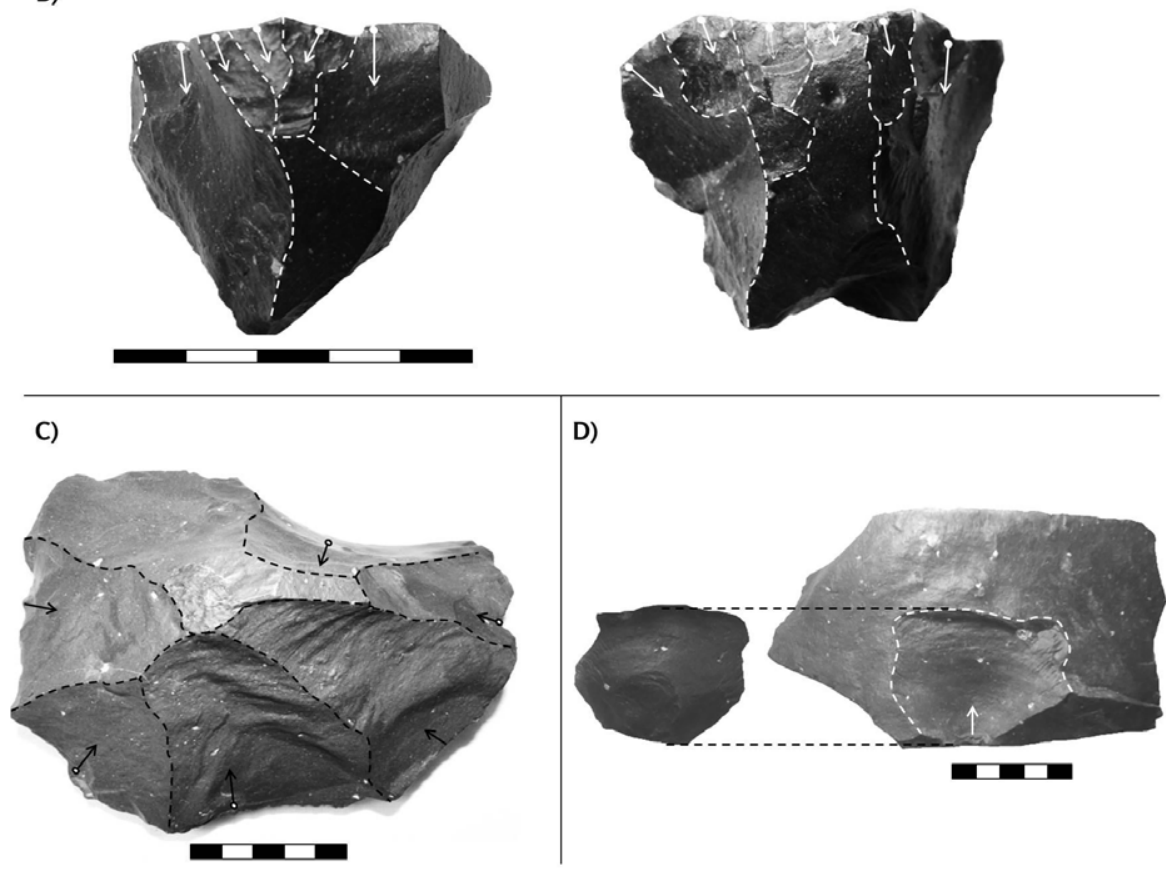

Figura 7. A) y B) núcleos piramidales atípicos; C) núcleo discoidal irregular; D) nucleiforme.

\begin{tabular}{|l|c|c|c|c|c|c|c|}
\hline \multirow{2}{*}{ Grupos } & \multicolumn{2}{|c|}{ Dimensiones de los núcleos } & \multicolumn{2}{c|}{ Extracciones mayores } & \multicolumn{2}{c|}{ Extracciones menores } \\
\cline { 2 - 8 } & Longitud & Ancho & Espesor & Longitud & Ancho & Longitud & Ancho \\
\hline $\begin{array}{l}\text { Núcleos de lascados aislados y } \\
\text { poliédricos }\end{array}$ & 9 & 10,6 & 4,3 & 5,3 & 6 & 3,5 & 4,3 \\
\hline $\begin{array}{l}\text { Núcleos bifaciales de lascados } \\
\text { alternantes y no alternantes }\end{array}$ & 9 & 6,2 & 3,1 & 3,6 & 4,1 & 2,3 & 2,5 \\
\hline $\begin{array}{l}\text { Núcleos con extracciones } \\
\text { unifaciales y bifaciales combinadas }\end{array}$ & 8,8 & 5,3 & 3 & 3,3 & 3,8 & 2,3 & 2,5 \\
\hline $\begin{array}{l}\text { Núcleos de extracciones } \\
\text { bidireccionales y/o } \\
\text { unidireccionales sobre uno o más } \\
\text { frentes de extracción }\end{array}$ & 6,6 & 5,3 & 2,5 & 2,7 & 3 & 1,7 & 1,9 \\
\hline $\begin{array}{l}\text { Núcleos piramidales atípicos y } \\
\text { núcleo discoidal irregular }\end{array}$ & 3,9 & 7,6 & 5,2 & 4,6 & 4,7 & 2,3 & 2 \\
\hline Nucleiformes & 7,9 & 8,1 & 3,3 & 3,8 & 4,4 & 2,2 & 2 \\
\hline
\end{tabular}

Tabla 3. Dimensiones promediadas de núcleos y sus negativos de lascado (en centímetros). 
superficies expuestas de estas piezas de gran tamaño para su reducción (facetas y planos naturales de las rocas). Prueba de ello son los núcleos sobre bloques que poseen una sola extracción o núcleos de lascados aislados. Por otro lado, habría sido necesario desarrollar una estrategia de trabajo cooperativo entre varias personas para girar los bloques de vulcanitas y así desempeñar correctamente el proceso de talla. Evidencia de este tipo de acciones son los núcleos poliédricos sobre bloques de gran tamaño dispersos en la superficie de POZAC. En este sentido, trabajos cooperativos de individuos en canteras han sido documentados por Barkai y Gopher (2009), Burton (1984) y Hampton (1997), tanto para casos etnográficos como arqueológicos. Así, en POZAC, los procedimientos empleados para manejar los recursos habrían implicado acciones no solo individuales sino también colectivas, abarcando operaciones organizadas en razón de un "aprovisionamiento cooperativo" (Goren-Inbar, 2011).

En relación a los instrumentos empleados para desarrollar la acción (Sinclair, 2000), se puede mencionar el hallazgo de fragmentos de percutores con tamaños entre 10 y $15 \mathrm{~cm}$ - de peso considerable - que habrían sido de utilidad para fragmentar bloques de grandes dimensiones. Al respecto, Escola (1993) documentó el uso de percutores con pesos próximos - y mayores- a los 1.000 gr para explotar bloques de grandes dimensiones en canteras de la microrregión de Antofagasta de la Sierra. Los procedimientos de explotación de estas grandes masas rocosas habrían requerido que el/la tallador/a impactara la superficie con nódulos rodados o facetados de cuarcita o vulcanita (Colombo, 2013; Toth, Clark y Ligabue, 1992). Técnicas de reducción como el quarrying, definido por Toth et al. (1992), habrían sido de utilidad en estos eventos de talla. A través de esta técnica se balancea un percutor grande entre las piernas para impactar el borde de un bloque de basalto y así extraer lascas; o bien, él o los individuos, podrían haberse posicionado frente a los bloques de materia prima que apoyan directamente sobre el sedimento para luego ejercer una percusión directa con un percutor de tamaño y peso considerables (Binford y O'Connel, 1984). Trabajos experimentales realizados por Colombo (2013) pusieron en evidencia la aplicación de estos tipos de técnicas para fracturar bloques de cuarcita de gran tamaño en canteras arqueológicas del centro de Tandilia (Buenos Aires, Argentina), ya sea que el/la artesano/a empleara una o dos manos para sujetar la pieza o bien, de forma alternativa, arrojara el percutor sobre el bloque de materia prima. En efecto, los bloques de vulcanitas de POZAC habrían sido trabajados a partir de distintos procedimientos técnicos que implicaron gestos y posturas particulares de los/as artesanos/as, ya sea que se buscara fragmentar la materia prima para reducir su tamaño, o bien extraer lascas grandes para ser usadas como formas-base.

Por otra parte, cabe destacar que durante las prospecciones realizadas en POZAC se documentaron casos de bloques de vulcanitas fracturados naturalmente por acción de crioclastía. Las fisuras y fracturas generadas por estos procesos de meteorización podrían haber sido aprovechadas por los/as talladores/as a través del uso de percutores, o bien mediante cuñas líticas y/o palancas introducidas en el cuerpo de la roca para expandir las fisuras. El uso de este tipo de instrumentos en canteras para fracturar los bloques de materia prima fue documentado por Bloxam y Heldal (2008), Colombo (2013), Singer (1984) y Torrence (1984), entre otros. Una vez obtenidos los fragmentos de menor tamaño habrían sido transportados fuera de la cantera o se habrían empleado como núcleos o nucleiformes en la cantera misma.

En un trabajo previo, Bobillo y Hocsman (2015) postularon que la búsqueda de formasbase de gran tamaño podría vincularse con un Complejo cazador-recolector pleno y en tránsito a la producción de alimentos, donde se habría requerido de lascas de gran tamaño para la manufactura de bifaces y puntas de proyectil lanceoladas apedunculadas de tamaños considerables. Este tipo de materiales se documentó en los sitios Quebrada Seca 3 y Cueva Salamanca 1, datados entre los 8000 y los 6000 años AP (Martínez, 2003; Pintar, 2009). Además, la intención de obtener lascas grandes a partir de bloques podría 
relacionarse con la manufactura de puntas de proyectil lanceoladas apedunculadas de tamaño similar (PCh F), presente en contextos residenciales con fechas entre $4500 \mathrm{y}$ 3000 años AP, aproximadamente (Hocsman, 2006, 2010). Bifaces de estas características dimensionales se empleaban también en la confección de cuchillos y raederas sobre bifaces (Hocsman, 2006). Asimismo, extracciones de módulo grandísimo documentadas en los núcleos fijos de gran tamaño podrían relacionarse con la búsqueda de formas-base para la manufactura de los denominados cuchillos/raedera de módulo grandísimo, que se presentan entre los 1.600 y los 1.200 años AP (Escola, Hocsman y Babot, 2013). Esta última tecnología se vincularía con un Complejo de sociedades agro-pastoriles plenas (Bobillo y Hocsman, 2015).

Ahora bien, además de la explotación de bloques de grandes dimensiones también se han aprovechado nódulos rodados, facetados y tabulares de vulcanitas con dimensiones menores a $30 \mathrm{o} 40 \mathrm{~cm}$. La gestión de este tipo de piezas (móviles) durante el proceso de talla implicó procedimientos técnicos y formas de manipulación de las plataformas de percusión y superficies de extracción diversas. Aschero $(1986,1988)$ planteó que nódulos de tamaño considerable pudieron haberse fragmentado mediante una técnica de bloque contra bloque como las descriptas por Crabtree (1972) y Flenniken y White (1985) y sometidas a experimentación por Colombo (2013). Según los autores, a través de este tipo de técnica es posible fragmentar la materia prima y extraer lascas grandes y espesas. Por otra parte, se podría haber empleado una técnica de apoyo de la pieza sobre el sedimento para percutir el borde de la misma con un nódulo rodado o facetado de cuarcita o vulcanita (Binford y O'Connel, 1984; Colombo, 2013) o bien adoptando métodos de talla por percusión sostenida (Colombo, 2013; Crabtree, 1972; Prous, 2004). En relación a este último tipo de procedimiento, los gestos aplicados mediante una talla por percusión sostenida se evidencian a partir del hallazgo de percutores con dimensiones inferiores a los $10 \mathrm{~cm}$, útiles para efectuar trabajos sobre nódulos grandes, medianos y/o pequeños, frecuentemente disponibles en PPZAC. Así, la posibilidad de manipular el recurso lítico para su reducción —nódulos con tamaños inferiores a los $30 \mathrm{~cm}$ o lascas nodulares- habría permitido distintos tipos de gestión como parte de un debitage simple (sensu Inizan et al., 1999), de acuerdo a las intenciones de los sujetos. En consecuencia, diferentes cadenas operativas productoras de lascas (sensu Martín Blanco et al., 1994) se habrían gestado como parte de la dinámica tecnológica.

En un trabajo anterior, Bobillo (2017) documentó el uso de formas-base de tamaños entre 4 y $8 \mathrm{~cm}$ para la manufactura de instrumentos descartados en POZAC y PPZAC. En este sentido, formas-base con dimensiones inferiores a las requeridas para la manufactura de bifaces, puntas de proyectil o cuchillos/raedera también fueron buscadas por los individuos para la elaboración de diversos toolkits. Como parte de esta diversidad se puede considerar la confección de instrumentos de distintos tipos y función: cuchillos, cortantes, raspadores, raederas, muescas, perforadores, escoplos, gubias, entre otros. Así, en los contextos líticos de las canteras analizadas existieron distintos métodos de manipular y explotar los recursos líticos en función del tipo de lascas que se buscaba extraer para ser empleada como forma-base. Los rangos de tamaño fueron variables, yendo desde lascas muy grandes hasta lascas medianas-pequeñas y/o pequeñas. En consonancia con esta última observación debe tenerse en cuenta, por ejemplo, el caso de los núcleos de extracciones unifaciales bidireccionales y unidireccionales sobre uno o más frentes de extracción, ya que presentan la particularidad de que la mayoría de los negativos de lascado corresponden a lascas de tamaño pequeño (Figura 6). Ante esta situación, es factible contemplar la posibilidad de que algunos métodos y técnicas de talla "específicas" se desarrollaran en función de la obtención de lascas con determinados tamaños, en este caso, medianas pequeñas y/o pequeñas. Este proceso de búsqueda de formas-base difiere con lo observado en otros conjuntos de núcleos, los cuales se emplean para extraer lascas medianas-grandes, grandes y muy grandes (Figura 3), además de pequeñas. En este sentido, el aprovisionamiento de recursos 
líticos no se basó en procedimientos estáticos y uniformes, sino que implicó distintos criterios y habilidades (Schlanger, 1990, 2005), ya sea que se encuentren o no orientadas a extraer determinados productos mediante las actividades de talla.

De este modo, el tratamiento dado a los distintos tipos de núcleos, mediante técnicas de talla simple, multifacial, bifacial y centrípeta (Boëda, 1993; Gallego y Rubio Jara, 1996; Inizan et al., 1999; Martín Blanco et al., 1994; Santoja, 1984), además de las piezas que presentan gestiones particulares como ser los núcleos de lascados unifaciales y bifaciales combinados y los núcleos de extracciones unifaciales bidireccionales y unidireccionales sobre uno o más frentes de extracción, refleja prácticas y modos de hacer específicos (Lemonnier, 1992). En relación a esto, se considera que el accionar de los/as artesanos/as en situaciones de aprovisionamiento implica habilidades, conocimientos tecnológicos y experiencias prácticas particulares (Ingold, 1990). Así, en las canteras y canteras-taller, se entabla una relación activa y sensorial entre el practicante y el material, donde la habilidad se manifiesta no sólo como la aplicación mecánica de una fuerza externa, sino como un monitoreo constante (Sinclair, 2000) y un acto reflexivo (Ingold, 2000).

Por último, y en el orden de las ideas anteriores, debe contemplarse que PPZAC y POZAC constituyen palimpsestos, es decir, espacios líticos que han sido utilizados y re-utilizados durante milenios de ocupación de la localidad de Punta de la Peña. En consecuencia, al analizar los datos empíricos de canteras surgen patrones de actividad vinculados con procesos de corta o larga duración (o complejos de cantera) (Bloxam y Heldal, 2008). Para el caso de las canteras aquí abordadas, se definió un lapso de explotación de los recursos líticos que iría desde los 8000 a los 1200 años AP aproximadamente (cf. Bobillo y Hocsman, 2015). Por lo tanto, la diversidad observada en la muestra de núcleos no sólo refleja las distintas prácticas que los sujetos desarrollaron como parte de las actividades de aprovisionamiento, sino que también serían el testimonio de distintas acciones y formas de trabajar los recursos materiales a lo largo del tiempo. En tal sentido, datos provenientes de núcleos recuperados en sitios con estratigrafía y que cuenten con dataciones absolutas serán fundamentales para brindar mayor claridad sobre la temporalidad de las prácticas de reducción en canteras, considerando la base de datos tipológica reunida en el presente estudio. Así, en futuras investigaciones se buscará reconocer esta diversidad de núcleos y el empleo de formas-base en sitios residenciales y/o logísticos, esto permitirá comprender y situar la amplia gama de elecciones de los individuos y grupos que participaron en la construcción y transformación de los sistemas tecnológicos a través del tiempo (Dobres, 2000; Torrence, 2001).

Para concluir, a partir de esta investigación se logró efectuar una reconstrucción de las distintas prácticas de reducción de núcleos que habrían utilizado las personas durante milenios de explotación y re-explotación de recursos líticos. En este sentido, la información reunida en canteras de la localidad de Punta de la Peña permitió aportar datos sobre las múltiples formas de conceptualizar y trabajar los recursos líticos en la microrregión de Antofagasta de la Sierra en particular y en la Puna Argentina a nivel regional. De acuerdo a las interpretaciones realizadas, se hace evidente que un estudio detallado de la materialidad que conforman los contextos líticos de canteras y canterastaller permite tomar conocimiento sobre el conjunto de materiales seleccionados para las actividades de talla, las técnicas o procedimientos utilizados por los/as artesanos/as, los implementos usados para desarrollar la acción y el producto final buscado (Sinclair, 2000).

\section{Agradecimientos}

A Salomón Hocsman por los aportes y comentarios realizados durante el análisis de los conjuntos líticos. A Valeria Olmos, Alfredo Calisaya, Leandro Bitti, Gustavo 
Espadoni, Fernando Villar, Ariel Escobedo, Martín Alderete, Roy Casañas, Mauro Grezzana, Wilfredo Faundes, Luca Sitzia y Ximena Power por su colaboración con las actividades de campo en PPZAC y POZAC. A la familia Morales por su hospitalidad. A los evaluadores por sus comentarios y recomendaciones. Este trabajo se realizó en el marco de los proyectos PIUNT G503 y PIP-CONICET 577 (dirigidos por Carlos A. Aschero) y PICT 1703 (dirigido por Salomón Hocsman). El contenido de este trabajo es mera responsabilidad de los autores. 


\section{Referencias citadas}

» Aschero, C. A. (1975). Ensayo para una clasificación morfológica de artefactos líticos aplicada a estudios tipológicos comparativos. Informe al CONICET. Manuscrito inédito.

" Aschero, C. A. (1983). Ensayo para una clasificación morfológica de artefactos líticos aplicada a estudios tipológicos comparativos. Apéndices A-C. Manuscrito inédito.

»Aschero, C. A. (1986). Estudio antropológico integral de una región de la puna Argentina: Antofagasta de la Sierra. Manuscrito inédito.

" Aschero, C. A. (1988). Arqueología precerámica de Antofagasta de la Sierra. Quebrada Seca: una localidad de asentamiento. Manuscrito inédito.

» Aschero, C. A., Elkin, D. y Pintar, E. (1991). Aprovechamiento de recursos faunísticos y producción lítica en el Precerámico Tardío. Un caso de estudio: Quebrada Seca 3 (Puna Meridional Argentina). Trabajo presentado en el XI Congreso Nacional de Arqueología Chilena. Santiago de Chile, Chile.

» Aschero, C. A., Escola, P. S., Hocsman, S. y Martínez, J. (2002-2004). Recursos líticos en la escala microregional Antofagasta de la Sierra. Arqueología, 12, 9-36.

» Aschero, C. A., Manzi, L. y Gómez, A. (1993-1994). Producción lítica y uso del espacio en el nivel 2b4 de Quebrada Seca 3. Relaciones de la Sociedad Argentina de Antropología, XIX, 191-214.

» Barkai, R. y Gopher, A. (2009). Changing the face of the earth: Human behavior at Sede Ilan, an extensive Lower-Middle Paleolithic quarry site in Israel. En B. Adams y B. Blades (Eds.), Lithic Materials and Paleolithic Societies (pp. 174-185). Oxford: Blackwell Publishers.

» Barros, M. P., Messineo, P. G. y Colantonio, M. J. (2015). Chert quarries and workshops in the Humid Pampa sub-region: New contributions on exploitation techniques and circulation through study of chaînes opératoires. Quaternary International, 375, 99-112.

» Binford, L. R. y O'Connell, J. (1984). An Alyawara Day: The stone quarry. Journal of Anthropological Research, 70(3), 406-432.

»Bloxam, E. y Heldal, T. (2008). Identifying heritage values and character-defining elements of ancient quarry landscapes in the Eastern Mediterranean: An integrated analysis. QuarryScapes report, Deliverable 10, http://www.quarryscapes.no

"Bobillo, F. M. (2015). Aprovisionamiento de recursos líticos: reducción de núcleos y extracción de formas-base en canteras de vulcanita (Antofagasta de la Sierra Catamarca). La Zaranda de Ideas. Revista de Jóvenes Investigadores en Arqueología, 13, 9-24.

"Bobillo, F. M. (2017). Estudio comparativo de Zonas de Aprovisionamiento y Cantera (ZAC) de Punta de la Peña (Antofagasta de la Sierra, Catamarca): análisis de las actividades de talla en una cantera y cantera-taller. Intersecciones en Antropología, 18, 67-77.

» Bobillo, F. M. (en prensa). Estrategias tecnológicas empleadas en la explotación de materias primas y formatización de artefactos en Pampa Oeste Zona de Aprovisionamiento y Cantera (Antofagasta de la Sierra - Catamarca, Argentina). Chungara. Revista de Antropología Chilena.

"Bobillo, F. M. y Hocsman, S. (2015). Mucho más que solo aprovisionamiento lítico: actividades en canteras y prácticas sociales en las fuentes de Pampa Oeste, Quebrada Seca y Punta de la Peña (Antofagasta de la Sierra, Catamarca). Revista del Museo de Antropología, 8, 23-44. 
» Boëda, E. (1993). Le débitage discoïde et le débitage Levallois récurrent centripède. Bulletin de la Société Préhistorique Française, 90(6), 392-404.

» Burton, J. (1984). Quarrying in a Tribal Society. World Archaeology, 16(2), 234-247.

»Colombo, M. (2013). Los cazadores recolectores pampeanos y sus rocas. La obtención de materias primas líticas vista desde las canteras arqueológicas del centro de Tandilia. (Tesis Doctoral inédita), Universidad Nacional de La Plata, Argentina.

»Crabtree, D. E. (1972). An introduction to flintworking. Occasional Papers of the Idaho State University Museum, 28, 1-98.

»Dobres, M. A. (2000). Technology and social agency: outlining a practice framework for archaeology. Oxford: Blackwell Publishers.

»Elías, A. (2010). Estrategias tecnológicas y variabilidad de los conjuntos líticos de las sociedades tardías en Antofagasta de la Sierra (Provincia de Catamarca, Puna Meridional Argentina). (Tesis Doctoral inédita), Universidad de Buenos Aires, Argentina.

»Ericson, J. E. (1984). Toward the analysis of lithic production systems. En J. E. Ericson y B. A. Purdy (Eds.), Prehistoric Quarries and Lithic Production (pp. 1-9). Cambridge: Cambridge University Press.

»Escola, P. S. (1993). De percusión y percutores. Palimpsesto, 3, 33-51.

»Escola, P. S. (2000). Tecnología lítica y sociedades agropastoriles tempranas. (Tesis Doctoral inédita), Universidad de Buenos Aires, Argentina.

»Escola, P. S. (2003). Disponibilidad de recursos líticos y fuentes de aprovisionamiento en un sector de la puna meridional. Mundo de Antes, 3, 65-86.

»Escola, P. S., Hocsman, S. y Babot, M. P. (2013). Entre las residencias y los campos de cultivo. Aporte de los cuchillos/raederas de módulo grandísimo a la cuestión del laboreo agrícola en Antofagasta de la Sierra (Puna de Catamarca) durante el primer milenio d.C. Relaciones de la Sociedad Argentina de Antropología, XXXVIII(1), 83-110.

»Flenniken, J. J. y White, J. P. (1985). Australian flaked stone tools: a technological perspective. Records of the Australian Museum, 36(3), 131-151.

» Funes Coronel, J. A. y Martínez, J. G. (2013). Lithic production sequences in the southern Argentinian Puna during the initial middle Holocene: Quarry-workshop characterization in the mid-course of the Ilanco River. Quaternary International, 307, 74-80.

» Gallego, J. P. y Rubio Jara, S. (1996). Propuesta de análisis tecnomorfológico para la industria lítica del Pleistoceno medio. Espacio, Tiempo y Forma, Serie I, Prehistoria y Arqueología, 9, 33-76.

» Goren-Inbar, N. (2011). Culture and cognition in the Acheulian industry: a case study from Gesher Benot Ya,aqov. Philosophical Transactantions of the Royal Society B, 366, 1038-1049.

» Hampton, O. W. (1997). Rock Quarries and the Manufacture, Trade, and Use of Stone Tools and Symbolic Stones in the Central Highlands of Irian Jaya, Indonesia: Ethnoarchaeological Perspectives. (Tesis Doctoral inédita), Texas A\&M University, Estados Unidos.

» Heldal, T. (2009). Constructing a quarry landscape from empirical data. General perspectives and a case study at the Aswan West Bank, Egypt. Geological Survey of Norway, 12, 125-155.

»Hocsman, S. (2006). Producción lítica, variabilidad y cambio en Antofagasta de la Sierra (5500-1500 AP). (Tesis Doctotal inédita), Universidad Nacional de La Plata, Argentina.

» Hocsman, S. (2010). Cambios en las puntas de proyectil durante la transición de cazadores-recolectores a sociedades agro-pastoriles en Antofagasta de la Sierra (Puna argentina). Arqueología, 16, 59-86. 
" Hoguin, R. (2014). Secuencia cronológica y tecnología lítica en la Puna seca y salada de los Andes Centro-Sur para el Holoceno Temprano y Medio a través del ejemplo de Susques. Relaciones de la Sociedad Argentina de Antropología, XXXIX(2), 333-364.

"Ingold, T. (1990). Society, Nature and the Concept of Technology. Archaeological Review from Cambridge, 9, 5-17.

»Ingold, T. (2000). Making Culture and Weaving the World. En P. M. Graves-Brown (Ed.), Matter, Materiality and Modern World (pp. 50-71). Londres: Routledge.

»Inizan, M. L., Reduron-Ballinger, M., Roche, H. y Tixier, J. (1999). Technology and Terminology of Knapped Stone. Préhistoire de la Pierre Taillée. Nanterre: Cercle de Recherches et d'Etudes Préhistoriques (CREP).

» Lemonnier, P. (1992). Elements for an Anthropology of Technology. Ann Arbor: University of Michigan Press.

"López, G. E. J. (2013). Ocupaciones humanas y cambio a lo largo del holoceno en abrigos rocosos de la Puna de Salta, Argentina: una perspectiva regional. Chungara. Revista de Antropología Chilena, 45(3), 411-426.

» Manzi, L. (2006). Estrategias y formas de uso del espacio en poblaciones cazadorasrecolectoras de la Puna meridional argentina. Oxford: BAR International Series 1465.

"Martínez, J. G. (2003). Ocupaciones humanas tempranas y tecnología de caza en la microrregión de Antofagasta de la Sierra (10000-7000 AP). (Tesis Doctoral inédita), Universidad Nacional de Tucumán, Argentina.

» Martín Blanco, P., Jimenez Manzanares, A., Sanguino González, J. y Gómez Laguna, A. J. (1994). Identificación de cadenas operativas líticas en el sitio arqueológico de "Xasa de la Mina II" (Argamasilla de Alba, c. Real). Consideraciones acerca de los yacimientos superficiales sin contexto estratigráfico. Zephyrvs, XLVII, 15-40.

» Mercuri, C. y Glascock, M. (2010). Primeros datos sobre la procedencia de obsidiana de un sitio formativo de Santa Rosa de los Pastos Grandes, Puna de Salta, Argentina. Arqueología, 17, 247-258.

» Messineo, P. G. y Barros, M. P. (2015). Lithic raw materials and modes of exploitation in quarries and workshops from the center of the Pampa Grasslands of Argentina. Lithic Technology, 40(1), 3-20.

»Morello, F. (2005). Tecnología y métodos para el desbaste de lascas en el norte de Tierra del Fuego: los núcleos del sitio Cabo San Vicente. Magallania, 33(2), 29-56.

"Moreno, E. (2011). Tecnología de caza en la Quebrada de Antofalla, Departamento Antofagasta de la Sierra, Catamarca. Revista del Museo de Antropología, 4, 17-32.

" Pintar, E. (1996). Prehistoric Holocene Adaptations to the Salt Puna of Northwestern Argentina. (Tesis Doctoral inédita), Southern Methodist University, Estados Unidos.

" Pintar, E. (2009). Un "ecorrefugio" en la cuenca de la Laguna de Antofagasta (Puna Salada) hacia 7900 y 6200 años AP. Arqueología, 15, 85-108.

» Pintar, E. (2014). Continuidades e hiatos ocupacionales durante el Holoceno Medio en el borde oriental de la Puna Salada, Antofagasta de la Sierra, Argentina. Chungara. Revista de Antropología Chilena, 46, 51-71.

»Prous, A. P. (2004). Apuntes para análisis de industrias líticas. Ortigueira: Fundación Federico Maciñeira. 
» Ratto, N., Orgaz, M., De la Fuente, G. y Plá, R. (2002). Ocupación de pisos de altura y contexto de producción cerámica durante el Formativo: El caso de la región puneña de Chaschuil y su relación con el Bolsón de Fiambalá (Depto. Tinogasta, Catamarca, Argentina). Estudios Atacameños, 24, 51-69.

» Restifo, F. y Patané Aráoz, C. J. (2017). Artefactos Saladillo de la puna de la provincia de Salta (Argentina): interpretación del proceso de cambio tecnológico hacia fines del Holoceno Medio a partir de su clasificación funcional macroscópica. Relaciones de la Sociedad Argentina de Antropología, XLII(1), 13-34.

»Santoja, M. (1984). Los núcleos de lascas en las industrias paleolíticas de la meseta española. Zephyrvs, XXXVII-XXXVIII, 17-33.

» Schlanger, N. (1990). Techniques as human action: Two perspectives. Archaeological review from Cambridge, 9(1), 18-26.

» Schlanger, N. (2005). The Chaîne Opératoire. En C. Renfrew y P. Bahn (Eds.), Archaeology: key concepts (pp. 18-23). Londres: Routledge.

»Shipton, C. B. K., Petraglia, M. D. y Paddayya, K. (2009). Stone tool experiments and reduction methods at the Acheulean site of Isampur Quarry, India. Antiquity, 83, 769-785.

»Sinclair, A. (2000). Constellations of knowledge: human agency and material affordance in lithic technology. En M. A. Dobres y J. E. Robb (Eds.), Agency in Archaeology (pp. 196213). Londres: Routledge.

»Sinclair, A. y McNabb, J. (2005). All in a day's work: Middle Pleistocene individuals, materiality and the lifespace at Makapansgat, South Africa. En C. Gamble y M. Porr (Eds.), The Hominid Individual in Context (pp. 176-197). Londres: Routledge.

»Singer, C. A. (1984). The 63-kilometer fit. En J. E. Ericson y B. A. Purdy (Eds.), Prehistoric Quarries and Lithic Production (pp. 35-48). Cambridge: Cambridge University Press.

» Tchilinguirian, P. (2008). Paleoambientes holocénicos en la puna austral, provincial de Catamarca $\left(27^{\circ} \mathrm{S}\right)$ : Implicancias geoarqueológicas. (Tesis Doctoral inédita), Universidad de Buenos Aires, Argentina.

» Torrence, R. (1984). Monopoly or direct access? Industrial organization at the Melos obsidian quarries. En J. E. Ericson y B. A. Purdy (Eds.), Prehistoric Quarries and Lithic Production (pp. 49- 64). Cambridge: Cambridge University Press.

» Torrence, R. (2001). Hunter-gatherer technology: macro and microscale approaches. En C. Panter-Brick, R. Layton y P. Rowley-Conwy (Eds.), Hunter-gatherers: An interdisciplinary perspective (pp. 73-98). Cambridge: Cambridge University Press.

"Toselli, A. (1998). Selección de materias primas líticas y organización tecnológica en el sitio Punta de la Peña 4 (PP4), Depto. Antofagasta de la Sierra, Prov. de Catamarca. (Tesis de Licenciatura inédita), Universidad Nacional de Tucumán, Argentina.

» Toselli, A. (1999). Andesita variedad 1, ¿cuestión de disponibilidad o de calidad? En C. Aschero, M. Korstanje y P. Vuoto (Eds.), En los Tres Reinos: Prácticas de Recolección en el Cono Sur de América (pp. 51-60). Tucumán: Magna publicaciones.

» Toth, N., Clark, J. y Ligabue, G. (1992). The last stone axe-makers. Scientific American, 267, 88-93.

» Yacobaccio, H. D., Escola, P. S., Pereyra, F. X., Lazzari, M. y Glascock, M. D. (2004). Quest for ancient routes: obsidian sourcing research in Northwestern Argentina. Journal of Archaeological Science, 31, 193-204. 